\title{
Las ineludibles monjas del Buen Pastor en la cárcel de mujeres (Uruguay-1898-1989)
}

\author{
The unavoidable nuns of the Good Shepherd in the women's prison (Uruguay-1898-1989) \\ Graciela Sapriza \\ Centro de Estudios Interdisciplinarios Uruguayos (CEIU), Facultad de Humanidades y Ciencias de la Educación \\ (FHCE), Universidad de la República, Uruguay \\ gracielasapriza@gmail.com
}

\section{ReSUMEN:}

Reconstruir la historia de la cárcel de mujeres en Uruguay resulta difícil dado que a la escasa visibilidad en los documentos de época, se suma una singular situación en el Uruguay del novecientos; la de un país que destinaba la vigilancia de las mujeres delincuentes a la Orden del Buen Pastor de Angers y al mismo tiempo radicalizaba su proceso de secularización hasta extremos anticlericales, ordenando retirar los crucifijos de los hospitales (1906), aprobando la Ley de divorcio (1907) y suprimiendo la enseñanza religiosa de las escuelas públicas (1909). En 1929 en el marco de un nuevo impulso reformista de sectores progresistas del país y cuando el Parlamento discute una nueva ley sobre cárceles, se produce un intento de controlar a las monjas y modificar el gobierno de la cárcel de mujeres. Resulta de sumo interés analizar estas disputas entre las damas católicas, obispos y religiosas y los argumentos de diputados, médicos y jóvenes abogadas "positivistas" en esos enfrentamientos, aunque el resultado fuera negativo ya que la situación siguió incambiada, tanto que las religiosas continuaron administrando la cárcel hasta 1989. Este hecho plantea un campo dilemático que constituye el cerno de reflexión del artículo.

Palabras ClaVe: Mujeres presas, Monjas del Buen Pastor, Secularización, Uruguay.

\section{AbStract:}

Reconstructing the history of the women's prison in Uruguay is difficult given the scarce visibility in the documents of the time, a unique situation in the Uruguay of the nineteenth century is added; the one of a country that destined the surveillance of the delinquent women to the Order of the Good Shepherd of Angers and at the same time it radicalized its process of secularization until anticlerical ends, ordering to retire the crucifixes of the hospitals (1906), approving the Law of divorce (1907) and suppressing the religious education of public schools (1909). In 1929, within the framework of a new reformist impulse of progressive sectors of the country and when Parliament discussed a new law on prisons, there was an attempt to control the nuns and modify the government of the women's prison. It is of great interest to analyze these disputes between Catholic, bishop and religious ladies and the arguments of deputies, doctors and young "positivist" lawyers in these confrontations even if the result was negative since the situation remained unchanged, so much so that the religious continued to administer the jail until 1989.

KEYWORDS: Women offenders, Sisters of the good Shepherd, Secularization, Uruguay.

\section{Presentación ${ }^{1}$}

Construir un relato sobre la prisión femenina en Uruguay nos enfrenta a su ausencia en los discursos institucionales y su escasa visibilidad en los documentos. La dificultad se incrementa al intentar decodificar el "sentido de la pena" ya que ésta castiga en forma discriminada a varones y mujeres delincuentes. Resulta un trabajo específico indagar en la consideración del crimen marcado por el género y avanzar en la definición de diferentes regímenes de castigo para distintas transgresiones a la ley. Llama la atención la escasa elaboración / o registro/ sobre las prisiones femeninas en América Latina que comparen con los procesos de secularización de las cárceles de varones. Aun cuando existen una serie de contribuciones teóricas sobre la relación del género y el delito originarios de la criminología crítica tanto como del feminismo. ${ }^{2}$ 
La dificultad en relacionar el delito a la condición femenina y la persistencia de no registrar las instituciones de castigo para las mujeres es un rasgo que encontramos en diferentes tiempos y lugares. Invisibilidad que es una constante tanto en Argentina ${ }^{3}$ como en Uruguay. ${ }^{4}$

El penalista uruguayo Roberto Mathó Regusci atribuía esa ausencia a que la Cárcel para mujeres era administrada "admirablemente" por las monjas del Buen Pastor (desde 1889). Sin miedo a lo superlativo, consideraba que la obra desarrollada en la cárcel de Cabildo integraba, "uno de los más honrosos capítulos en la historia de la penología nacional".5

La orden del Buen Pastor, fundada en Francia por María Eufrasia Pelletier, ${ }^{6}$ se proponía como misión reformar a "la mujer de vida irregular". En América del Sur, se radicaron inicialmente en Chile y se extendieron por el continente hasta llegar a Colombia donde fundaron varias instituciones (García Amezquita, 2015). La Orden se había instalado en Uruguay en 1876 pero fue expulsada por resistirse a la Ley de Conventos en el período de Máximo Santos (1880-1885). ${ }^{7}$ Regresan al país a fines del siglo por intercesión o negociación del poeta Juan Zorrilla de San Martín ante el gobierno de Julio Herrera y Obes (1890-1894). El Ejecutivo, presidido por Juan Idiarte Borda, presentó un proyecto de ley en 1896 que fue informado por el senador J. L. Cuestas en el que afirmaba "se impone [la creación de un recinto carcelario para mujeres] porque la deficiencia del sistema actual reclama que las desgraciadas mujeres que caen bajo la acción de la justicia por delitos o faltas tengan una cárcel especial donde purgar su culpa”. ${ }^{8}$ El historiador José Pedro Barrán ya había señalado una incongruencia al observar que, "en 1898, el Patronato de Damas aconsejó al anticlerical Presidente Cuestas y este aceptó entregar la dirección interna de la Cárcel de mujeres a las religiosas del Buen Pastor" (Barrán, 1990, T. II, p. 86).

Resulta particularmente contradictorio que el Estado dejara en manos de una orden religiosa la gestión de la cárcel de mujeres y simultáneamente ordenara retirar los crucifijos de los hospitales (1906), aprobara la Ley de divorcio (1907) y suprimiera la enseñanza religiosa de las escuelas públicas (1909), entre otras medidas para excluir a la Iglesia Católica del espacio público.

Frente a ese escenario, la continuidad de la administración carcelaria en manos religiosas durante todo el siglo XX (1898-1989) resulta por lo menos enigmática y, a su vez, establece un delgado hilo entre épocas disímiles que se tensa en la constante de mantener a las mujeres transgresoras bajo la tutela del Estado a través de la religión. Situación comparable con lo sucedido en Argentina como señala D’ Antonio:

El proceso de secularización que afectó al Estado no tuvo en todos los casos los mismos efectos, por lo menos si de mujeres se trata. La transformación se produjo progresivamente en el marco de una asociación del Estado secular con la masculinidad, que al mismo tiempo identificó lo religioso con lo femenino, y, por lo tanto, promovió que las mujeres permanecieran bajo la tutela de la Iglesia. (D’ Antonio, 2013, p. 21).

El liberalismo propulsor de la modernidad es un rasgo compartido entre los dos países sobre todo en lo que refiere a la secularización de las instituciones del Estado. Se observa en ellos idéntico impulso reformista, aunque en Uruguay las posiciones liberales fueron más radicales y sus dirigentes enfrentaron tempranamente a la Iglesia Católica culminando, en 1919, con la separación de la Iglesia y el Estado, a través de la nueva Constitución que se puso en vigencia en ese año.

Resulta obvio remarcar que falta mucha investigación -en un área que apenas despunta- para poder discriminar el grado de difusión y/o de aplicación de la criminológica positivista (y su carga discriminatoria contra el género femenino) que habilite a evaluar las características de la modernización punitiva en el país. Aun así, resulta nítida la división entre los tratamientos destinados a varones y mujeres en los establecimientos correccionales. El dispositivo se orientaba a la rehabilitación moral que debía lograr la transformación de las mujeres delincuentes en "señoras honradas"; es decir, que aceptaran su destino de ser buenas amas de casa y/ o empleadas domésticas, de acuerdo a sus orígenes de clase.

El artículo pretende mostrar los contenidos específicos de género de la pedagogía aplicada por las monjas este análisis se realiza a través del establecimiento de una línea de tiempo en la que se identifican dos hitos 
relevantes a los que se suma una coda, en el novecientos, al final de los veinte y durante la última dictadura, en la consideración de la secularización/modernización punitiva y en los que la variable (excepción) será el tratamiento destinado a las mujeres y su persistente continuidad a lo largo del siglo. ${ }^{10}$

\section{Paradojas de la modernidad}

La abolición de la pena de muerte en 1907 (Ley No. 3238 del 23/09/1907) marca el fin de los castigos del cuerpo y la consolidación de la privación de libertad como eje de nuestro sistema penal, poniendo el foco en los propósitos regeneradores (rehabilitadores) de los establecimientos penitenciarios. El presidente de la Comisión a estudio del Código Penal (1882), Joaquín Requena, ya había definido que los objetivos de la cárcel debían ser la regeneración moral del delincuente y la aplicación de una rígida disciplina reformadora. Según algunas perspectivas analíticas, apelar a la moral tendría raíces cristianas que provendrían de la versión del Krausismo aportado por la destacada criminóloga española Concepción Arenal (1820-1893), ${ }^{11}$ doctrina en pugna con las corrientes positivistas que despuntaban en Uruguay en el período.

El contexto de aprobación del Código Penal (1889) también es el del enfrentamiento de diferentes doctrinas de castigo frente al crimen, la más importante, los pronunciamientos a favor o en contra de la pena de muerte. ${ }^{12} \mathrm{La}$ abolición de la pena de muerte se enmarca en el proceso de reformas impulsado durante el primer periodo de gobierno de José Batlle y Ordóñez (1903-1907) y estuvo precedida por un impactante juicio público "el caso Almeida" llevado adelante por el destacado abogado y Defensor de Oficio Dr. Pedro Figari; en ese juicio logró demostrar la inocencia del inculpado y la arbitrariedad de una pena que podría haber castigado con la muerte a un inocente. ${ }^{13} \mathrm{El}$ juicio tuvo un impacto formidable en la opinión pública, solo comparable al de Dreyfus desarrollado contemporáneamente en Francia.

La criminología positivista de la época y su aplicación en la psiquiatría constituye un rasgo característico de la modernización y el higienismo imperante en el Novecientos. Las ideas de Antonio Lombroso ${ }^{14}$ y su determinismo relacionado con el delito tuvieron una amplia difusión en el Río de la Plata en los primeros años del siglo, en circunstancias en las que se recibían constantes oleadas de inmigrantes y el aumento de la delincuencia, la trata de blancas y el predominio de mafias internacionales generaba uno de los núcleos más "necesitados" de control social. ${ }^{15}$

El saber criminológico italiano en sus múltiples facetas no solo se acoge y reelabora de manera original en las Repúblicas del Plata sino que, además, sus adeptos locales a menudo consiguen influir en las políticas reformistas del estado liberal, sobre todo en el ámbito penal y penitenciario y hasta consiguen su materialización en un perfecto panóptico como el de la "Penitenciaría Modelo", inaugurada en 1888, que pronto mostró sus fallas. ${ }^{16}$

La difusión de estas ideas contó, además, con el entusiasmo de sus propagandistas. El abogado y criminólogo italiano Enrico Ferri visitó por dos veces estos países en giras de conferencias con gran impacto en el medio (1908 y 1910). ${ }^{17}$ Pietro Gori, periodista, poeta, dramaturgo y un destacado dirigente anarquista, fue uno de los más fervorosos difusores de las ideas de Lombroso (Vidal, 2010); ${ }^{18}$ aun cuando el "delincuente" prototípico para las policías rioplatenses del novecientos era el "anarquista” incriminado por subvertir el orden público, persecución que se acentuó a partir de la revolución rusa en 1917 y la participación en ella de los anarquistas llamados "maximalistas". 19

\section{2. a. El "lobby" de las Damas de sociedad}

En América Latina, la construcción de sus Estados nacionales se dio en paralelo a la formación de sociedades de beneficencia y de caridad formadas por mujeres. Una forma de compensar por la vía de los 
hechos su exclusión de la vida política. Los espacios legítimos de participación eran escasos, el hogar, la Iglesia y la beneficencia eran los únicos donde podían actuar. Las "damas de sociedad" encontraron allí un lugar de reconocimiento y de ejercicio de poder. La radicación de la Orden del Buen Pastor para hacerse cargo de la cárcel de mujeres en el Uruguay laico es un buen ejemplo de cómo gestionaron esa parcela de autoridad. ${ }^{20}$

El Estado tomó esa decisión bajo la presión de esas influyentes damas católicas, pero también existieron razones prácticas que inclinaron la balanza a favor de las religiosas. Todo el mundo estaba de acuerdo en el "peligro moral" que significaba dejar en manos de hombres la administración de las cárceles de mujeres, pero el Estado no contaba en su burocracia con personal femenino entrenado y dispuesto a vivir con las internas/prisioneras. En cambio, las monjas que ya estaban segregadas en conventos y bajo reglas severas, eran percibidas como naturalmente adaptables al régimen penitenciario. No se debe descartar el hecho de que, para cubrir las expensas, el Estado debía aportar una proporción menor que la gastada en las prisiones para hombres ya que las monjas gobernarían la institución con el personal que la propia orden podía proporcionar.

$\mathrm{Al}$ contrario de la criminalidad masculina, que requería una batería de especialistas y estudios técnicos, el desvío moral (crimen de las mujeres) podía ser enderezado adecuadamente con los recursos que ofrecía la religión. Estas ideas pueden explicar cómo los líderes de la secularización pudieron tolerar las prácticas religiosas de las mujeres de sus propias familias: en su perspectiva, la Iglesia debía replegarse de la esfera pública y privatizarse en áreas domésticas. Con igual sesgo se podría considerar la vigencia de la "doble moral" sexual. En las élites urbanas, este estricto código moral se reforzaba con la devoción y educación religiosa para las jóvenes aun cuando esta contradijera los principios sostenidos por sus padres en la cátedra, el periodismo o la política porque de esa manera se conseguían "buenas madres de familia". ${ }^{21}$ Por supuesto, estas consideraciones prácticas se sustentaban en un conjunto de conceptos previos. Las mujeres no representaban una cifra importante en el total de los arrestos y muchas de ellas eran percibidas como criminales ocasionales; víctimas de su debilidad moral, resultado de su irracionalidad y falta de inteligencia. Por encima de estos argumentos, se encontraba el peso de las consideraciones de género y clase compartidas por igual por monjas y dirigentes políticos.

Las sociedades de beneficencia integradas por las damas de sociedad tenían detrás a la Iglesia Católica (y su numen, Monseñor Mariano Soler ${ }^{22}$ ). Por eso, el Estado batllista intentó transmutar la caridad cristiana en filantropía cívica, aprobando la Ley de Asistencia Pública Nacional, en 1911. A partir de ese momento, el Estado restringió la actividad de la beneficencia y asumió el control con criterio filosófico y político. El Estado comenzó a limitar el rol del voluntariado y de la Iglesia organizando el Consejo del Patronato de delincuentes y menores en 1915 (modificado en 1934 con la creación del Patronato de delincuentes y excarcelados). Varias personalidades políticas integraron el organismo como el jurista José Irureta Goyena, Juan Carlos Gómez Folle (durante años jefe de policía de Montevideo), incluso Luis Batlle Berres, futuro presidente de la República. Quedó así pautada la arena en la que se enfrentaron, en diferentes circunstancias y con diversos argumentos, ambos contendientes.

\section{2. b. Fundamentos de la cárcel del Buen Pastor}

El primer libro de Anales del Buen Pastor relata los pormenores de la ceremonia de inauguración de la cárcel, ${ }^{23}$ en el transcurso de la cual hizo uso de la palabra el "poeta de la patria", Dr. Juan Zorrilla de San Martín. Detalla la nómina de asistentes, presidida por Monseñor Mariano Soler, quien dio inicio a la ceremonia con la bendición de la capilla. Los padrinos, "la Sra. Catalina O’Neill de Fernández como Presidenta del Patronato de Damas y el sr. Gral. Don Nicomedes Castro Ministro de Gobierno en representación del Poder ejecutivo" (Mattó, 1962, p. 171). Las familias Buxareo, Errazquin, Heber Jackson, Gallinal y Zorrilla de San Martín fueron, entre otras, pertenecientes al patriciado, "padrinos" de las obras del Buen Pastor. 
El 15 de enero de 1899, la congregación recibió el primer aporte de reclusas: 14 procesadas al que se sumarían otras 10 más tarde. $\mathrm{Al}$ año siguiente se mudaron al edificio de la calle Cabildo que ya será el definitivo. Definitiva también quedó la organización de las reclusas mujeres regida por los principios morales del catolicismo más que por las modernas premisas del penitenciarismo (Fessler, 2012, p. 144). Indudablemente, el aporte de las Damas de Caridad fue muy significativo, pero su labor se enraizaba en un discurso caritativo basado en una visión clasista y alejado de la realidad de las condiciones de vida de los sectores populares, ya que estos eran considerados antisociales, amorales, vulnerables y necesitados de redención y orientación de las élites (Sánchez, 2006, p. 164). Se trataba de "rescatar" a la mujer y al niño (como un binomio inseparable) pero se ponía énfasis en que las mujeres debían ser "salvadas”. Como señala María José Correa, "las mujeres...fueron relegadas del espacio de las estrategias penitenciarias ortodoxas y conducidas a la corrección en sociedades religiosas" (Fessler, 2012, p. 141). Monseñor Mariano Soler, la máxima jerarquía eclesiástica, escribía sobre las internas, "Esas pobres jóvenes en quienes es bien sabido que sus defectos más comunes son la sensualidad, la desvergüenza, la pereza, la intriga, la mentira, y hasta un instinto sanguinario..." (Soler, 1901, p. 9). Las monjas compartían esa mirada estigmatizante hacia sus internas. En 1914, la superiora de la orden dirigía una carta al Presidente de la Comisión de Caridad de Niñas que permite ver qué opinión tenía sobre las menores:

En casos numerosísimos se trata de seres terriblemente depravados, degenerados por el vicio, física y moralmente enfermos, terreno fértil al desenfreno de todas las pasiones. ¡Son lo que para muchos constituye la hez de la sociedad, que desprecia y arroja lejos de sí como si para estas almas desgraciada hubiera muerto toda esperanza de redención!” [....] Y ¿̇cuán delicada es, señor Presidente, nuestra tarea; cuán difícil nuestra lucha contra el arraigo del mal? En los primeros tiempos todas las circunstancias nos son desfavorables. Los malos hábitos, las costumbres depravadas, los recuerdos del pasado vergonzoso, el cambio brusco del escenario y ambiente (...) todo fermenta con espantosa ebullición en el cerebro de las recluidas. ${ }^{24}$

Quedaba, así, matrizada una regla para el tratamiento de las mujeres en conflicto con la ley, que asociaba el delito al pecado que debía ser castigado con la reclusión. El trabajo y la disciplina, por su parte, eran privilegiados por Mariano Soler que se dirigía a las religiosas en estos términos:

Como la ocupación es la mejor manera de conservar la disciplina y el orden, distribuís su tiempo en lecciones de enseñanza elemental, en los quehaceres domésticos y en las labores propias de la mujer, como la costura, hiladas, tejidas, bordadas y similares, a fin de que, al salir del Asilo, sepan ganarse honestamente la vida. Y lo que no podíais descuidar, porque es la base de su regeneración, las instruís en las prácticas piadosas. ${ }^{25}$

El Buen Pastor daba importancia al trabajo, pero las características de las tareas realizadas por las internas, tales como lavar, planchar, tejer, bordar, las preparaban para encontrar ocupación solamente como empleadas domésticas. Las internas eran "colocadas" en casas de familia como sirvientas. Destino mencionado repetidamente por las autoridades como el mercado de trabajo más adecuado para las internas pobres.

El diputado Dr. Alberto Cima dirá, en 1929:

el Patronato dedica toda su actividad en proporcionarles sirvientes a las familias de Montevideo y aún de campaña -buenas, malas, bien tratadas o maltratadas, hay que colocarlas, las familias las exigen (destacados nuestros). ${ }^{26}$

Se suponía, así, que el trabajo las retornaría a su lugar, al lugar de clase y de género que les correspondía ocupar. No bastará rehabilitarlas como personas adaptadas -disciplinadas- para la sociedad, sino que habrá que hacer de ellas "verdaderas" mujeres, "madres": sumisas, obedientes y altruistas (Nari, 2000, p. 16).

\section{2. c. Flores del $\mathrm{Mal}^{27}$}


Casi todos los delitos cometidos por las mujeres (o los que se consideraban "delitos") se relacionan con el uso del cuerpo, la sexualidad femenina o la actitud hacia su descendencia hacia la que debía manifestar elesperado "apego" o la esperada ternura a riesgo de ser considerada una madre "desnaturalizada" de no hacerlo. El jurista uruguayo Dr. Pedro Figari, sin embargo, introdujo un sesgo humanista en sus consideraciones sobre las causas del infanticidio al recordar un patético caso.

Me tocó defender a una chica de catorce años, la que, mientras cebaba mate al patrón, un estanciero que iba entretanto recorriendo de un lado a otro un corredor, se siente mal, entra a su pieza, alumbra; despavorida envuelve a su criatura en una sábana; sale de inmediato para seguir su tarea y cuando puede volver hacia la cría, encuentra que ya es cadáver: ¡infanticidio! $[\ldots]$.

No hay que sublevarse contra esta adversidad, porque pudo la pobre chica pasar un tiempo en la cárcel, acaso los mejores días de su vida. Contra lo que hay que sublevarse es contra el hecho de que sea mucho mejor la vida de la cárcel que la de la libertad, en medio de las enormes, cuantiosas riquezas de la campaña, y que eso sea así para la mujer principalmente que es la que debería ser más protegida, no solo en razón de su estructura sino de su propia misión, que es tan esencial como trascendente para la raza. (Figari, P. citado por Sanguinetti, 2013, p. 106).

El socialista José Ingeniero, considerado un referente entre los influyentes juristas y médicos higienistas uruguayos, en su libro "Criminología" (1913) es mucho más duro en sus juicios basados en 6 años de observación en el Instituto de Criminología. ${ }^{28}$ Ejemplifica a los anómalos congénitos a través de un conjunto de casos de varones, cita un único caso femenino exponiéndolo como el de "una loca moral" (categoría común entre los alienistas de la época que describía conductas desviadas de la moral aceptable). Es interesante observar cómo la criminología positivista modeló el tema al “naturalizar” los sentimientos femeninos. El caso tratado era el de una mujer huérfana de padre y madre, abandonada en un asilo que posteriormente trabajó de sirvienta, ${ }^{29}$ y además había ejercido la prostitución "sin amar a ningún hombre” y que había cometido abortos. Condenada por infanticidio, el único remordimiento que manifestaba era por no haber tomado precauciones para evitar el embarazo. Ingenieros remataba:

Fácilmente se advierte que en esta infanticida hay una ausencia congénita de sentido moral, reflejada en su falta de sentimientos sociales, maternales, de amistad, de amor, etc. En los amorales congénitos, la condición delictuosa es un resultado de profundas causas orgánicas: nacen predestinados a no adaptar su conducta a la moral del medio en que viven (el énfasis es nuestro). ${ }^{30}$

Lila Caimari rescata el estudio de Ingenieros para demostrar cómo actuaba el determinismo al concluir que,

La incapacidad de actuar durante las entrevistas de acuerdo con los cánones de normalidad moral previstos para las mujeres de su condición, convertía a esta infanticida en un caso de irreversible atavismo psicopatológico. (Caimari, 2012, p.149).

Contemporáneamente, con mayor o menor énfasis, las feministas hicieron oír su voz en la disputa sobre las "desviaciones" femeninas, oponiéndose incluso a las corrientes deterministas imperantes en la época y sentando su posición frente a los así considerados “crímenes” femeninos.

\section{2. d. Las feministas intervienen en el debate}

En 1906, se realizó el Congreso Internacional del Libre Pensamiento, en Buenos Aires, en el que participaron destacados intelectuales europeos y de la región. La maestra María Abella, una feminista "liberal" uruguaya, presentó allí un petitorio de 17 puntos que fue aclamado de pie, aun cuando los postulados eran escandalosamente "radicales" como declarar en uno de ellos que la "mujer soltera y mayor de edad es dueña de sí misma: su cuerpo es lo que más legítimamente le corresponde, puede hacer de ello lo que quiera, como el hombre" (Abella de Ramírez, 1906), extendiéndolo al ejercicio de la prostitución y abominando de su castigo como expresó en el punto 14: "Suprimir las cárceles llamadas del Buen Pastor, en que se martiriza la mujer por el delito de amar". ${ }^{31}$ Sumando el punto 12, "suprimir la prisión por adulterio, pues este puede considerarse un delito de amor, y se ha dicho que por amor no se castiga". ${ }^{32}$ 
Paulina Luisi, creadora del Consejo Nacional de Mujeres y luchadora contra la "doble moral" burguesa, denunció la "trata de blancas" (concepto de época en referencia a redes internacionales de tráfico de mujeres) y se embarcó en la campaña "abolicionista”, imprimiendo un tono más modoso a su intervención. Recibió su título de médica en 1908 y fue la primera uruguaya en completar una carrera universitaria. El cuerpo médico, en pleno proceso de legitimación, asumió como propio el rol de creador de normas morales, intentando disciplinar las "pulsiones" de los sectores subalternos: niños, locos y sectores populares; también de las mujeres. En 1913, el presidente José Batlle y Ordóñez le encomendó estudiar medidas de higiene social en Europa. En su estadía en Francia, estuvo en contacto con el movimiento feminista en plena efervescencia. Regresó de Europa dispuesta a comprometerse en distintas campañas a favor de la mujer, a impulsar la educación sexual, a combatir la "lacra social" del prostíbulo.

La prostitución resignificó el doble código moral, localización de las fantasías masculinas sobre el sexo prohibido y al mismo tiempo culpabilización de la mujer. Desde diversas posiciones filosóficas y religiosas, se abordaba un tema que había adquirido dimensiones inesperadas en la región platense donde la inmigración masiva había desequilibrado la paridad de los sexos -las estadísticas registraban un alto índice de masculinidad- y en el que simultáneamente se procesaba una acelerada transición demográfica que impuso el retraso en la edad del matrimonio. Dos factores que exacerbaron las prácticas "perversas" de la sexualidad: la masturbación y la prostitución, objetos privilegiados del saber médico de la época.

Paulina Luisi trató el tema desde el sitial que le otorgaba una jerarquía indiscutible, "Observamos desde la cumbre en que nos hallamos felizmente colocados como aquellas van rodando por las faldas de la montaña social antes de tocar el fondo cenagoso del arroyo". 33 "Nosotras, las mujeres, nos rebelamos contra un concepto social que hace de nuestro sexo el inmundo cáliz de los más repugnantes apetitos”, contrastando en "sexo" y "cáliz" los dos significados, el de ser mujer y, a la vez, un perverso objeto de deseo. ${ }^{34}$

La "trata de blancas" generaba redes internacionales de contrabando de mujeres. Paulina publicó "Una voz clamando en el desierto" (1918) en el que acusaba a la doble moral por reducir a las mujeres a ser santas o pecadoras. Rechazó las ideas de Lombroso en cuanto a que "la ramera es la representante en el sexo femenino del tipo criminal en el hombre". Concluyó que era la miseria la causa más eficiente de todas las que se confabulaban para arrojar a millares de mujeres a la prostitución... "Seducción, insuficiencia de salarios, abandono de la infancia y trata de blancas, he ahí las verdaderas fuentes de esas llagas sociales". ${ }^{35}$

El escaso salario era una razón de peso, dice la historiadora Ivette Trochon en su investigación sobre la prostitución en la región (Trochon, 2003), aunque señala que no se debería simplificar el enfoque e incluso animarse a deconstruir las leyendas acerca de las "Estercitas", las "flores de fango" del bajo alimentadas y difundidas por el tango (Trochon, 2003, p. 137). Esas Magdalenas arrepentidas eran el sueño de redención soñado por la fundadora de la Orden, quizás el mismo de las monjas que gobernaban la cárcel del Buen Pastor en Montevideo. A finales de la década del veinte, las hermanas de caridad administraban una población de alrededor de 400 mujeres (niñas, adolescentes y adultas) y ello se debe a que los jueces derivaban a la Institución a niñas huérfanas o abandonadas o en situación de calle. En ese huit clos, ${ }^{36}$ se mezclaban diferentes condiciones y situaciones.

Las monjas distribuían en secciones bien delimitada por un código moral a las internas de acuerdo al informe extremadamente elogioso que realizó el diputado del Partido Nacional Rogelio Mendiondo de su visita al Buen Pastor en 1929, institución que catalogó como modelo por su organización y disciplina. Destacaba que las "pensionadas" - 400 mujeres vigiladas por 28 hermanas de caridad y 16 ayudantas- se hallaran clasificadas en tres secciones según su coeficiente de moralidad. En la $3^{a}$ Sección, se asilaban menores no contaminadas, muchachas de 18 años o más y aun niñas pequeñas, en la $2^{\mathrm{a}}$, estaban todas aquellas que habían cometido en "un momento de extravío (...) deslices en la vida" pero que conservaban todavía restos de vergüenza de su vida pasada; en la $1^{\text {a }}$ Sección se alojaba el peor elemento -ladronas, homicidas, etcétera- en fin, todas aquellas que la justicia arrancaba "de la ciénaga más negra y tortuosa del vicio" (Trochon, 2003, p. 174) 
Las “ovejas descarriadas", ladronas, estafadoras y prostitutas eran enviadas al Buen Pastor para ser "reformadas" y en ese campo se debatieron las diferentes pedagogías para reencauzarlas. Si para las religiosas, el crimen debería "purgarse" por medio de reglas morales estrictas que conseguirían la redención del pecado aplicando una batería de normas: disciplina rígida/ orden, vigilancia, trabajo, silencio/, y la práctica religiosa "que ayudaba mucho" a reubicarlas el lugar de clase y género que les correspondía.

Las feministas, al contrario, plantearon reconsiderar que se entendía por "crimen". María Abella lo hizo tempranamente, reclamando "no castigar a la mujer por amar", incluyendo "disponer" del propio cuerpo como los varones. La leader feminista Paulina Luisi, desde su posición abolicionista, denunciaba las causas (pobreza, engaño, doble moral) viendo en las circunstancias que rodeaban a la prostitución un efecto más de la opresión femenina. Unos años más adelante, la connotada feminista Sara Rey Álvarez ${ }^{37}$ se interesó por la infancia y por las mujeres "delincuentes" e intentó torcer el rumbo de la gestión del Asilo y la cárcel femenina en 1929 cuando integraba el Consejo del Patronato de delincuentes y menores. Su intervención se enmarca en la discusión parlamentaria de un nuevo Proyecto de Ley sobre cárceles que se desarrollaba en esos meses en un nuevo contexto político.

\section{EL “SEGUNDO IMPULSO” REFORMISTA Y LAS POLÍTICAS DEL CRIMEN}

En 1929, se asiste a un nuevo empuje "reformista" de los sectores progresistas de la corriente batllista con un claro contenido anticlerical de parte de algunos integrantes del cuerpo legislativo. El historiador José Pedro Barrán lo expresó claramente: "Hubo /.../ un último impulso de ese reformismo inquietador de estructuras y el pacto entre batllistas y nacionalistas independientes, entre los años 1930, 1931 y 1932, parecieron revivir el fuego de los comienzos del reformista" (Barran, 1989, p.10).

En el marco de ese "segundo impulso", se aprueba la ley de sufragio femenino en diciembre de 1932. El golpe de Estado de marzo de 1933 cerró el ciclo de las reformas sociales, aunque algunas concreciones del periodo anterior vieron la luz luego de la ruptura institucional. Sucedió así con el nuevo Código Penal, que llevaba tres largos años de preparación y se aprobó en 1933, facilitando que la obra fuese asimilada a una realización del "terrismo"; ${ }^{38}$ concepto que dificulta la cabal comprensión de las modificaciones más importantes introducidas por el nuevo Código que, a mi juicio, fueron la despenalización del aborto y la eutanasia, penalizados nuevamente por Ley en 1938. Resulta interesante señalar que esta ley se aprobó gracias a la intervención de dos diputados católicos (minoría absoluta en el Parlamento) pero que logró la adhesión de otros sectores conservadores, "la sabiduría con la que jugaron estos inesperados actores del Uruguay laico, en una coyuntura que les favorecía ciertamente, explica el logro de interferir las "intenciones eugénicas" del codificador y de gran parte del elenco político de la época” (Sapriza, 2009, p, 84).

Este apunte, y este episodio crucial, permite entrever el poder, la fuerza moral que aún conservaba la Iglesia católica en el Uruguay secularizado a pesar de haber esplazado la religión católica a zonas más inicuas, o haberse "privatizado" a nivel de prácticas domesticas (Caetano y Geymonat, 1997). Y, a su vez, nos permite dejar trazada una interpretación acerca de la excepcional permanencia de la orden del Buen Pastor al cuidado de las delincuentes mujeres durante casi un siglo (1898-1989) que retomamos al final del artículo.

\section{3. a. Ciencia y diplomacia fascista}

En los años veinte, a pesar de la desaceleración del flujo migratorio, la llegada del fascismo y la pérdida de novedad de las teorías de Lombroso, continuaron los intercambios y la colaboración entre juristas, criminólogos y psiquiatras de Italia y del Río de la Plata en nombre de una "ciencia latina" que, si bien seguía anclada en el positivismo, era hostil al "materialismo anglosajón". 
En este período, el centro de la discusión se trasladó del ámbito criminológico al de la eugenesia ${ }^{39}$ y la medicina social gracias a la difusión de una nueva disciplina: la medicina constitucional y la difusión de las ideas de "biotipología" del científico genovés Nicola Pende -creador del término en 1930 — ${ }^{40}$ que en ese mismo año llegó al Río de la Plata en un viaje que combinaba intenciones científicas y propagandísticas. América Latina se había convertido en una baraja del juego diplomático italiano, los golpes de estado de 1930 habían dado lugar, en Argentina y Brasil, -1933, en Uruguay- a gobiernos conservadores, más en sintonía con el fascismo italiano que los anteriores. El Panamericanismo -impulsado desde los Estados Unidos-, interfirió este empuje expansionista del fascismo italiano. En ese contexto de luchas hegemónicas, propias de la entre-guerras (1918-1939), tuvo lugar la II Conferencia Panamericana de Eugenesia y Homicultura en Buenos Aires (1934), continuada con la de Población en 1940. Al comienzo de esa década, las ideas eugénicas habían impregnado las políticas públicas de ambos países La puesta en práctica de las políticas penales regeneradoras e higienistas se encarnan en la prolongada gestión de J. C. Gómez Folle en la Jefatura de policía (1926) acompañado por el destacado jurista Irureta Goyena redactor del nuevo Código Penal aprobado durante la dictadura de Gabriel Terra (1933-1938). Precisamente, durante la dictadura (1933), se creó la Dirección de Institutos Penales y se designó como Director a Gómez Folle. Debemos a su gestión la promoción de la Ley de "estado peligroso" de $1941 .{ }^{41}$ Para entonces, ya se había perdido el acento en la reforma social y esa corriente se asociaba a posiciones cada vez más conservadoras en todos los órdenes. ${ }^{42}$

Por otro lado, la concepción totalitaria que justificaba que el estado controlara la reproducción de sus ciudadanos fue asumida por un núcleo importante de personas aun cuando tuvieran ideas "progresistas". Entre ellos, se encontraba la feminista Sara Rey Álvarez que, en 1934, publicaba en el diario Ideas y Acción varios artículos referidos a la obligatoriedad del Certificado médico prenupcial. En uno de ellos, "La eugenesia en pro del racismo", extremadamente ambiguo, se pronunciaba sobre las leyes racistas alemanas recién aprobadas expresando, "comprendemos y sentimos la razón y la necesidad de ellas" si estas medidas eran para evitar la procreación de los enfermos, dementes e infelices. ${ }^{43}$

\section{3. b. El Circo Sarrasani en el debate sobre laicidad}

El Buen Pastor fue objeto, desde sus inicios, de varias campañas de denuncias, tanto desde sectores liberales como "revolucionarios". El "Mal Pastor" era denunciado, en marzo de 1917, como un "antro de castramiento moral" por el periódico anarquista La Batalla, dirigido por María Collazo. Más adelante, el diario comunista Justicia se hará eco de similares denuncias. Aunque las críticas más formales provendrán del propio recinto parlamentario.

En 1929, año en el que se discutía nuevamente en el Parlamento un proyecto para la construcción de un edificio destinado a cárcel de mujeres, se produjo una denuncia sobre la muerte de una menor en la institución y las Hermanas del Buen Pastor se negaron a dejar ingresar una comisión investigadora por considerar que se "invadían sus fueros". 44

Las intervenciones de los parlamentarios ponen en evidencia el deseo de esos sectores "liberales” por modificar o controlar el gobierno omnímodo de las hermanas del Buen Pastor. Los integrantes más activos del cuerpo legislativo son dos ex integrantes del Consejo del Patronato de delincuentes y menores: Luis Batlle Berres y Alberto Cima a los que se suma Justino Zavala Muniz. El Dr. Cima dejó claro en su exposición cuál era la intención de esta "interpelación” al Buen Pastor.

Todos nosotros sabemos qué es el régimen religioso donde puede ser impuesto por aquellos que creen antes que nada en su religión (...) y si las hermanas la tienen, impondrán ese régimen, como lo hacen en todas partes; pero nosotros, los que no tenemos esa fe religiosa, los que creemos que es un engaño, que es una mentira, no podemos a nombre del Estado ir a imponérselo a unas desgraciadas mujeres por el hecho de que sean delincuentes y procesadas. No podemos tolerar eso; tenemos que llegar a modificar ese sistema [destacados nuestros]. ${ }^{45}$ 
El 11 de julio se trae a luz un episodio ocurrido en 1925, cuatro años atrás. En ese entonces, Luis Batlle Berres - que integraba el Consejo del Patronato de delincuentes y menores- intentó llevar a un grupo de internas del Buen Pastor al Circo Sarrasani. ${ }^{46}$ Se suscitó, entonces, un duro intercambio entre la religiosa directora de la Institución Buen Pastor y el Consejo. Aunque las monjas consideraban que el espectáculo era "moral" y no lo cuestionaban, veían impropio que las niñas y jóvenes asistieran a un espectáculo público ya que el régimen en el que estaban era de reclusión. Batlle argumentó que la reclusión se sostenía al comienzo del establecimiento porque la institución recogía prostitutas o menores de edad que frecuentaban los prostíbulos, pero esa condición se había modificado debido a que los jueces derivaban al Buen Pastor niñas sin hogar o huérfanas, algunas muy pequeñas que pasar hasta 5 o 6 años sin salir jamás a la calle. El intercambio de notas continuó y la tensión llegó al extremo cuando la Directora del Buen Pastor amenazó con no admitirlas nuevamente si las internas iban al circo. Las monjas aducían que no era necesario el "roce" social como complemento de su educación (como argumentaba el Consejo) ¡sino que ya habían tenido un exceso de roce! ${ }^{47}$ Esta circunstancia, que podríamos llamar "el episodio del Circo Sarrasani”, tuvo consecuencias políticas ya que Batlle Berres presentó renuncia al Consejo al no sentirse respaldado en su gestión. Simultáneamente un antiguo integrante del Consejo del Patronato de delincuentes y menores, el Dr. Alberto Cima, publicó el libro "Protección del estado a las menores abandonadas o delincuentes" (1929) en que señaló las faltas cometidas por las monjas en la gestión de los establecimientos denunciando los castigos aplicados a las internas, en particular el del encierro en celdas "medievales". En su informe, incluyó también un apartado sobre las diversiones o la recreación en el Instituto dando cuenta de este insólito episodio; incursionando en una perspectiva pedagógica que incluía momentos lúdicos en la educación de las internas, a diferencia de la rígida disciplina impuesta por la Orden.

Al mismo tiempo que se desarrollaba el debate parlamentario, el periódico El Demócrata, de clara filiación católica, asumió la defensa de las religiosas en sucesivos artículos titulados "La verdad sobre el asilo del "Buen Pastor", publicados desde junio a comienzos del mes de agosto de 1929. En ellos, acusaba a los denunciantes por exhibir los "fines difamatorios de la masonería", sosteniendo que todo se resumía a "propaganda electoral". El periódico católico entendía que el folleto expresaba "La saña del Dr. Cima contra las Hermanas de Caridad”. ${ }^{48}$ El Demócrata, en su defensa de las hermanas de caridad, destacaba la intervención del diputado Justino Zavala Muñiz al que califican de "minúsculo Dantón de la Avenida Brasil" acusándolo de seguir, fielmente, las órdenes de su amo José Batlle y Ordónez a quien bautizan como el "Maquiavelo de Piedras Blancas", término que da cuenta de la virulencia del enfrentamiento entre confesionales y anticlericales, muchos de ellos de filiación masónica. El miércoles 24 de julio, publicaba y enumeraba los cargos señalados contra las Hermanas del Asilo, incluso detallándolos, estos eran: no dar instrucción a sus internas, obligarlas a rezar excesivamente, el recurso a castigos corporales, encerrar a las incorregibles, hacerlas trabajar (lavar, planchar, bordar, vainillar) y no entregarles el "peculio, ni siquiera cuando eran liberadas, y que salían cuando querían y volvían... madres (en el caso de las menores del Asilo). A todas estas acusaciones respondían justificando el proceder por la obediencia a la norma de la Orden: moral y trabajo.

Los artículos de defensa de las monjas en El demócrata denuncian las "Ideas geniales de una doctora reformista; Sara Rey Álvarez" haciendo mención al artículo publicado por ella en El Imparcial en el que acusaba directamente a las monjas de "explotación" de las internas. La autora enumeraba una lista de empresas y comercios que se beneficiaban con el producto de esta "mano de obra benévola": las grandes tiendas London-Paris y La Sirena, agregando que no remunerar el trabajo era una pésima practica pedagógica si se quería despertar el "amor al trabajo" en las internas que entonces lo verían como una mortificación innecesaria. Apuntaba, a su vez, la multiplicidad de oficios que se podían enseñar tales como, taquigrafía, dactilografía, aparado de cuero, fabricación de sombreros,

Luego de esta tormenta de acusaciones periodísticas y diatribas parlamentarias, las cosas siguieron sin modificar, tanto que las religiosas continuaron administrando la cárcel hasta 1989. Resulta evidente que los sectores "progresistas" no lograron imponer sus ideas sobre el tratamiento de la criminalidad 
femenina a los líderes políticos y la burocracia del sistema penitenciario. Aparentemente, ningún gobierno consideró prioritario controlar la rehabilitación de estas criminales. Quizá no consideraban la cárcel como lugar adecuado para la rehabilitación ya que se guiaban por ideas muy tradicionales acerca del lugar que correspondía a las mujeres. Determinados por sus prejuicios acerca de género, crimen y trabajo; más que por una teoría criminológica positivista. Y el peso o la influencia de las familias católicas pertenecientes al "patriciado" que apuntalaban y protegían la permanencia de la Orden a cargo de huérfanas, menores y "desviadas". Potencia moral de la religión católica en el Uruguay secularizado (ya destacada anteriormente en referencia a la penalización del aborto ,1938), a pesar de haberla "privatizado" a nivel de prácticas domésticas (Caetano y Geymonat, 1997). En definitiva, lo que sostenemos, es que el régimen punitivo impuesto por la Orden religiosa apuntaba al logro de un modelo femenino aceptado por la sociedad mesocrática uruguaya -que las propuestas de las corrientes opuestas suscribían en ese aspecto- lo que explicaría su permanencia a través del siglo; aun atravesando el periodo crucial de la dictadura cívico-militar (1973-1985) al que hacemos referencia en este último apartado.

\section{OTROS MUNDOS}

En el año 1968, ingresaron cinco presas políticas a la cárcel del Buen Pastor, otro mundo frente a las presas "comunes"; otros orígenes, otras pertenencias sociales y niveles educativos: "El grupo lo constituíamos dos estudiantes de Arquitectura, una estudiante de Medicina, una empleada bancaria y una Profesora de Secundaria” (Jorge, 1994, p. 25). Cientos de mujeres jóvenes acusadas de ser militantes en movimientos políticos subversivos invadieron las prisiones del Buen Pastor en Latinoamérica. En pocos años, la mayor parte de los institutos correccionales femeninos fueron puestos bajo el control del estado, como sucedió en Argentina de acuerdo al estudio de Debora D’ Antonio (2009, 2013); reacción que se produjo después de las espectaculares fugas de militantes guerrilleras de las cárceles del Buen Pastor de Córdoba y Buenos Aires (D’ Antonio, 2013, p. 31). En Uruguay, y aun luego de las dos fugas protagonizadas por militantes del MLN-T en 1970 y 1971 (acompañadas por la aún más espectacular de 111 hombres de la Cárcel de Punta Carretas, en 1971), las monjas continuaron administrando esa prisión para las presas comunes hasta 1989. Para el tratamiento de las militantes presas contaron con la presencia de policías militares femeninas hasta 1976 en que todas las prisioneras políticas fueron trasladadas al Establecimiento Militar de Reclusión No. 2 (Punta de Rieles).

La antropóloga Blanca Emeric (2013) logró entrevistar a la última directora del Buen Pastor -de la que no se proporciona el nombre- en ejercicio desde 1967 a 1989 cuando se desplazó a las religiosas. La monja describió una institución "ideal" en la que a pesar de tener más de 100 detenidas, "Era un hogar", "el ambiente era familiar como en una casa, había muchas plantas, canarios, gatos, se cuidaba todo" (Emeric, 2013, p. 97). Para Graciela Jorge, ex prisionera política, las monjas aplicaban una disciplina rígida sin concesiones, en la que solamente existían órdenes y rutinas... "no se puede hablar". "Convento y Cárcel, Cabildo albergaba varios mundos incomunicados” (Jorge, 1994, p. 19). Sin embargo, la monja directora recordó esos momentos con nostalgia y cierta candidez:

En un período tuvimos a las sediciosas en la cárcel, las teníamos repartidas en tres pabellones, pero se distorsionaba la relación con las otras mujeres, decidimos ponerlas a todas juntas, luego se fugaron. Como personas eran excelentes, pero teníamos ideas muy diferentes, nosotros las respetamos y ellas también fueron muy correctas con nosotras, fue un momento muy difícil para la cárcel y también para la congregación. (Emeric, 2013, p. 90).

Recién en 1989 -ya en pleno período democrático - la cárcel de mujeres dejó de ser administrada por las monjas y pasó a integrar el sistema nacional de cárceles y la atención de las reclusas quedó centrada en el sistema policial, perteneciente al Ministerio del Interior. La cárcel de mujeres, ya administrada por el Estado, siguió utilizando el viejo edificio - con todas sus reminiscencias de convento-, incluidos los calabozos de 
castigo calificados como "medievales" por nuestros legisladores de 1929. La ley "humanitaria" de cárceles, aprobada en 2011 por el gobierno del Frente Amplio, estableció que la administración de cárceles quedara en la órbita del Instituto Nacional de Rehabilitación (I.N.R) y el cuidado de las personas privadas de libertad en nuevxs funcionarixs civiles, "Operadores Penitenciarios".

Las trasformaciones sociales que se produjeron desde la segunda mitad del siglo determinaron cambios sustanciales en la condición de las mujeres. Se conquistó el sufragio y, paulatinamente, la integración a los partidos políticos. Este proceso se acompañó de fuertes transformaciones culturales en los años '60, expresiones como la música, vestimenta y actitudes hacia la sexualidad y la reproducción -facilitada por la píldora anticonceptiva - determinaron cambios en las subjetividades de amplios sectores de mujeres. La permanencia de la institución Buen Pastor, a pesar de esas transformaciones en la situación de las mujeres, plantea dilemas aún no resueltos. El texto propone interpretaciones tentativas en la búsqueda de esas "verdades" siempre esquivas cuando se trata de develar la opresión de género.

\section{Agradecimientos}

Quiero agradecer a mis evaluadoras anónimas de la revista Descentrada por sus significativas observaciones.

\section{REFERENCIAS}

Antony, C. (1998). Mujer y cárcel: el rol genérico en la ejecución de la pena. En R. Del Olmo (coord.), Criminalidad y criminalización de la mujer en la región andina (pp. 63-73). Caracas: Nueva Sociedad.

Baratta, A. (2000). El paradigma de género desde la cuestión criminal hacia la cuestión humana. En A. Ruiz (comp.), Identidad femenina y discurso jurídico (pp. 99-135). Buenos Aires: Biblos.

Barrán, J. P. (1989). Advertencia. En G. Caetano y R. Jacob (comp.), El nacimiento del terrorismo (1930-1933) (pp. 9-15). Montevideo: Ed. Banda Oriental.

Barrán, J. P. (1990). Historia de la sensibilidad en el Uruguay. El disciplinamiento (1860-1920) (Tomo 2). Montevideo: Ed. de la Banda Oriental.

Barrán, J. P. (2008). Intimidad, divorcio y nueva moral en el Novecientos. Montevideo: Ed. de la Banda Oriental.

Bohoslavsky, E. y Di Liscia, M. S. (comps.) (2005). Instituciones y formas de control social en América Latina, 1840-1940. Una revisión. Buenos Aires: Prometeo Libros.

Caetano, G. y Geymonat, R. (1997). La secularización uruguaya, 1859-1919. Montevideo: Taurus.

Caimari, L. (1997). ¿Whose Criminals are these? Church, State and Patronatos and the rehabilitation of female Convicts (Buenos Aires, 1890-1940). The Americas, 54(2), 185-208.

Caimari, L. (2012). Apenas un delincuente. Crimen, castigo y cultura en la argentina. 1880-1955. Buenos Aires: Siglo XXI.

Cima, A. (1929). Exposición y crítica de nuestro sistema penitenciario. Protección del Estado a las menores abandonadas o delincuentes. Montevideo: Imprenta Nacional Colorada.

Correa, M. J. (2005). Demandas penitenciarias. Discusión y reforma de las cárceles de mujeres en Chile (1930-1950). Historia, 31(8).

D’ Antonio, D. (2009). "Rejas, gritos, cadenas, ruidos, ollas". La agencia política en las cárceles del Estado terrorista en Argentina, 1974-1983. En A. Andújar; D. D’ Antonio; F. Gil Lozano; K. Grammático y M.L. Rosa (comps.), De minifaldas, militancias y revoluciones. Exploraciones sobre los 70 en la Argentina (pp. 89-108). Buenos Aires: Ed. Luxemburg.

D’ Antonio, D. (2013). Presas políticas y prácticas de control social estatal en la Argentina durante los años setenta. Revista Contemporánea, 4(4), 13-40. 
Emeric, B. (2013). Mujeres a la sombra y mujeres en la sombra. Inquietante extrañeza. Relatos de vida. Montevideo: Nordan Ed.

Fessler, D. (2012). Derecho penal y castigo en Uruguay (1878-1907). Montevideo: Comisión Sectorial de Investigación Científica, Universidad de la República.

García Amezquita, A. (2015). Pagando penas y ganando el cielo. Vida cotidiana de las reclusas de la cárcel El Buen Pastor 1890-1929. Historia y Memoria, 10, 75-96.

Guy, D. (2000). La casa correccional de mujeres como instituto de socorro infantil. En F. Gil Lozano, V.S. Pita y M.G. Ini (Dirs.), Historia de las mujeres en la Argentina Siglo XX (pp. 24-45). Buenos Aires: Taurus.

Harding, S. (1996). Ciencia y Feminismo. Madrid: Ediciones Morata.

Jorge, G. (1994). Historia de 13 palomas y 38 estrellas. Fugas de la Cárcel de mujeres. Montevideo: Tae editorial.

Larrandart, L. (2000). Control social, derecho penal y género. En H. Birgin (comp.), Las tramas del poder punitivo. El género del derecho penal (pp. 85-106). Buenos Aires: Biblos.

Nari, M. A. y Fabre, A. (Comp.) (2000). Voces de mujeres encarceladas. Buenos Aires: Catálogos.

Pintos, F. (1960). Historia del movimiento obrero del Uruguay. Montevideo: Suplemento de Gaceta de Cultura.

Pita, V. (2000). Damas, locas y médicas. La locura expropiada. En F. Gil Lozano, V.S. Pita y M.G. Ini (Dirs.), Historia de las mujeres en la Argentina. TI. Colonia y siglo XIX (pp. 273-293). Buenos Aires: Taurus.

Sánchez, M. (2006). Mujeres institucionalizadas por convicción y sujeción en las postrimerías del siglo XIX. Análisis de un caso: Asilo confesional de la Congregación Nuestra Señora de la Caridad del Buen Pastor. 1876-1923. Tesis de Maestría en Trabajo social (inédita). Montevideo: Facultad de Ciencias Sociales, Universidad de la República.

Sanguinetti, J. M. (2013). El Doctor Figari. Montevideo: Aguilar Ed.

Scarzanella, E. (1997). Criminologia, eugenesia y medicina social en el debate entre cientificos argentinos e italianos (1912-1941). Ponencia presentada al 49 Congreso Internacional de Americanistas, Quito.

Sapriza, G. (2001). "La Utopía eugenista" "Raza, Sexo y género en las políticas de población en el Uruguay (1920-1945)". Tesis de maestría. Montevideo: FHCE-Udelar.

Sapriza, G. (2009). El caso del aborto en el Uruguay de Terra (1933-1938). Revista Derecho Penal. Segunda Época, $10,79-85$.

Sapriza, G. (2016). La redención moral. Prisión femenina en Uruguay. En N. Montealegre (coord.), G. Sapriza y M.A. Folle (comp.), El Tiempo Quieto. Mujeres privadas de libertad en Uruguay (pp. 31-52). Montevideo: Csic-Udelar.

Vidal, D. (2010). Florencio Sánchez y el anarquismo. Montevideo: Ed. Banda Oriental.

Trochon, I. (2003). Las mercenarias del amor. Prostitución y modernidad en el Uruguay (1880-1932). Montevideo: Taurus.

\section{Notas}

1 Un avance del tema se publicó anteriormente en Sapriza (2016).

2 Sobre este tópico se puede consultar: Antony (1998), Baratta (2000) y Larrandart (2000).

3 Constituyen antecedentes valiosos las investigaciones sobre el tema realizadas en Argentina (entre ellos Caimari, 1997; D’ Antonio, 2013; Bohoslavsky y Di Liscia, 2005) y la observación de las cárceles del Buen Pastor en Chile realizadas por Correa (2005).

4 Ya en 1910 el historiador Roberto Levellier observó que los criminalistas habían ignorado la delincuencia femenina (Guy, 2000, p. 25). En 1962, Mathó Regusci arribaba a semejante conclusión respecto de Uruguay. Mathó Regusci, R. (1962). El establecimiento Correccional y de Detención para mujeres. Revista Penal y Penitenciaria, I(3), 2do semestre, pp. 163-192.

5 La razón la aportó en una carta, publicada en ese mismo número de la Revista Penitenciaria (1962), el Director General de Institutos penales, Ricardo Carreras: "mientras un recluso representa un costo diario de $\$ 25 .-$, una reclusa cuesta aproximadamente \$ 9."”. Carreras, R (1962). Cartas de los lectores, Revista Penal y Penitenciaria. Año I, No. 3, 2do semestre, p.194. 
6 La congregación del Buen Pastor fue fundada en Francia y aprobada con la bendición del Papa Gregorio XVI, el 16 de enero de 1835. La orden se expandió llegando a tener para el año 1868, ciento diez casas en todo el mundo. Se instalan en Chile en 1855, Ecuador 1871, Perú 1871, Argentina 1885 (García Amezquita, 2015, p. 21).

7 La Ley que habilitaba la inspección de los conventos y sobre todo la conocida Ley del matrimonio civil, también de ese año se cuentan entre otras medidas propias de un primer impulso de separación de la Iglesia y el Estado.

8 Cámara de Senadores de la República del Uruguay (1896). Diario de Sesiones, 10 de marzo. Montevideo: Imprenta Nacional, p. 277.

9 La historiadora Lila Caimari (1997) planteó igual paradoja para Buenos Aires, la discontinuidad entre los programas higienistas y rehabilitadores aplicados a los delincuentes hombres y la administración de la cárcel de mujeres por las monjas del Buen Pastor. Los dos países parten del mismo tronco histórico y coinciden en los procesos estructurales e ideológicos que pautaron las transformaciones de fines del siglo XIX difieren quizá en la radicalidad de determinados rasgos.

10 Se trabaja con un acumulo de fuentes (legislativas, prensa, documentos oficiales, libros de actas, entre otras) que hacen posible la interpretación de esos documentos a la luz de las teorías del conocimiento genéricamente marcadas (Harding, 1996, entre otras autoras).

11 Ambos pensadores tuvieron una profunda influencia en el ideario político de José Batlle y Ordóñez, dos veces presidente del Uruguay (1903-1907) (1911-1915) y orientador de un reformismo social que será matrizado como "batllismo" y así será citado en próximas referencias.

12 Dámaso Antonio Larrañaga presentó, en 1831, un proyecto abolicionista de la pena de muerte que, si bien nunca fue aprobado, constituye un valioso antecedente.

13 Pedro Figari (1861-1938), destacado abogado, político, educador, hoy día reconocido internacionalmente como uno de los más importantes artistas plásticos uruguayos. A medida que se desarrollaba el extenso juicio que se prolonga desde 1895 a 1905 fue elaborando su alegato contra la pena de muerte, estos se pueden leer en los siguientes estudios de Figari: Figari, P. (1899). El crimen de la calle Chaná. Publicaciones en defensa del Alférez Enrique Almeida. Montevideo Barreiro y Ramos. Figari, P. (1903). La pena de muerte. Conferencia leída en el Ateneo de Montevideo. 4 de diciembre de 1903. Imp. El Siglo Ilustrado. Figari, P. (1905). La pena de muerte. Veintidós artículos publicados en "El Siglo" de mayo a junio de 1905. Imp. Montevideo. El Siglo Ilustrado.

14 "L' Uomo Criminale" (1876) fue la obra fundadora de esta corriente que encontró en América Latina su ámbito de mayor legitimidad.

15 En Argentina, además de dirigir la revista “Archivos de psiquiatría, criminología y ciencias afines” (1909-1913) siguiendo el modelo de la revista italiana “Archivio di antropología criminale, psichiatria e medicina legale”, José Ingenieros dirigió el primer Instituto de Criminología. La Penitenciaría Nacional se organizó según los postulados del médico turinés. Desde 1914, Fernández y Loudet siguieron manteniendo contactos con estudiosos de Italia a través de la nueva "Revista de criminología, psiquiatría y medicina legal” (Scarzanella, 1997).

16 Su antecedente fue la Penitenciaría Nacional de Buenos Aires -1877- edificio que seguía el modelo de la prisión de Pentonville, en Inglaterra.

17 E. Ferri dictó sus conferencias en el Teatro Urquiza de Montevideo, en setiembre de 1908. Fue recibido por una delegación encabezada por el socialista Emilio Frugoni. El impacto de sus ideas fue recogido por los periódicos “progresistas” de la capital, entre ellos El Liberal. Belén de Sárraga, su directora, no se privó de discrepar con el "sabio" italiano en sus apreciaciones deterministas sobre la mujer. "La mujer no puede ser genio porque los crea", su 5a Conferencia, motivó el editorial titulado: "El continente no puede ser más pequeño que el contenido" (El Liberal, 11 de setiembre de 1908).

18 Daniel Vidal, "Florencio Sánchez y el anarquismo" (2010) consigna que, en 1902, la Revista Archivos de psiquiatría, criminología y ciencias afines editada en Argentina, dirigida por José Ingenieros y con Gori como redactor político, se distribuía en Montevideo y era leída con atención por los círculos más instruidos. En 1904, el semanario anarquista Futuro realizó una reseña del libro de Gori, La anarquía ante los tribunales (Vidal, 2010, p. 63).

19 Sobre esa persecución, Pintos, 1960, p. 72 y A.G.N. Caja No. 218, Foja 4, mayo 2 de 1919.

20 Aunque, como lo demuestra Valeria Pita en referencia a los "manicomios" en Argentina, este dominio fue puesto en tensión por el embate de administradores y médicos (Pita, 2000, p. 273-293).

21 El batllista Gabriel Terra, futuro presidente (y autor del golpe de estado de 1933), confesaba que aun existiendo "mujeres doctas" a las que admiraba prefería una educación católica para sus hijas sabiendo que era una doctrina "producto de la leyenda y la imaginación” pero con la que se prepararían "buenas madres de familia, abnegadas” (Barrán, 2008, p. 35).

22 El obispo Mariano Soler (1846-1908) presidió la Iglesia uruguaya en tiempos del Papa León XIII, autor de la Encíclica Rerum Novarum (1891) en la que se pronunciaba sobre las ideologías en pugna en Europa en ese período, el liberalismo y el socialismo. Soler tendrá una intensa actividad e incidencia en numerosos grupos sociales. En particular, sobre las damas de sociedad, intentó crear un "feminismo católico" (se dirigió también a los obreros en términos singulares alentándolos a organizarse) y contribuyó con sus pastorales y homilías a consolidar a las Damas Católicas que se organizaron para 
oponerse a la Ley de Divorcio (1907) y continuaron rechazando otras medidas innovadoras del gobierno de Batlle y Ordóñez.

23 El poder ejecutivo accedió entregando la dirección interna a las religiosas sin perjuicio que la superintendencia "le corresponde al Consejo Penitenciario sobre todos los establecimientos carcelarios que le está expresamente fijada por la ley de 4 de abril de 1891”. Acevedo, E. (1934). Anales Históricos del Uruguay. Tomo IV. Montevideo: Barreiro y Ramos, p. 485.

24 Isern, Juan. 1924. El Buen Pastor en las Naciones de Sud América. Tomo 2. Buenos Aires: Amorrortu, p. 263.

25 Soler, M. (1901). Apreciación del Asilo Buen Pastor de Montevideo. Montevideo: Tipografía uruguaya, p. 10.

26 Cámara de Representantes de la República del Uruguay (1930). Diario de Sesiones. XXX Legislatura. Tomo CCCLIII. Montevideo: Imprenta Nacional, p. 315.

27 Baudelaire, Charles (1857). Les fleurs du mal. Paris: Éditions Poulet-Malassis et de Broise.

28 Aunque en esta obra matizó algunas ideas sobre los rasgos psicopatológicos entendidos como un mal orgánico de su primera obra publicada en 1900 dando ahora mayor importancia a las variables sociales que eran las decisivas. Dividía a los delincuentes entre transitorios y congénitos. A pesar de esta evolución en su pensamiento no se sustrajo a los prejuicios acerca de las mujeres. En igual período el médico uruguayo Alfredo Giribaldi realizó el mismo tipo de estudios en su Oficina de Antropología e identificación antropométrica. Creada para el estudio psicosocial del individuo encarcelado se instaló en la cárcel de Miguelete.

29 Expresión de época para las personas que trabajaban al servicio de un patrón o una patrona.

30 Ingenieros, J. (1913). Criminología. Madrid. Daniel Jorro Editor. p. 132.

31 Programa mínimo de reivindicaciones femeninas. Presentado al Congreso internacional del librepensamiento en la ciudad de Buenos Aires en 1906 (Abella de Ramírez, 1906, p. 179-180).

32 Abella de Ramírez, M. (1965 [1906]). Ensayos feministas. Montevideo: Ed. El Siglo Ilustrado, p. 179-181.

33 Luisi, P. (1918). Un crimen social. "La trata de blancas”. Buenos Aires: Tribuna Libre, p. 138.

34 Ibídem, p. 139.

35 Ibídem, pp. 141-142.

36 Nota de edición: significa "A puertas cerradas".

37 Sara Rey Álvarez fundadora del Partido Feminista era presentada en una entrevista como miembro del Consejo del Patronato de delincuentes y menores. Junto a Julián Álvarez Cortés, presentó a la Comisión de la Cámara de Representantes un proyecto de reorganización de la protección a la infancia. Su interés por el feminismo se manifestó en una entrevista a Miss Pankhurst que se publicó en el periódico uruguayo “El Día”. A su regreso al país, en 1928, integró la Alianza Uruguaya de Mujeres; fundó, en 1932, el Comité Pro Derechos de la Mujer (ocupó el cargo de Presidenta) que, después de conquistarse el derecho al voto, se convirtió en Partido. Ideas y Acción, Órgano Oficial del Partido Independiente Demócrata Feminista. Año I, Número I, Montevideo, junio de 1933.

38 Encargado inicialmente al Colegio de Abogados por el Consejo Nacional de Administración, este designó para la revisión y modificación del antiguo Código al jurista José Irureta Goyena. El hecho - ¿coincidencia? - de que este último fuera unos de los más preclaros dirigentes de la reacción conservadora antibatllista y fundador de la Federación Rural, junto a Carlos Reyles, generó una confusión -que se arrastra hasta hoy-.

39 Esta corriente de pensamiento fue presentada por su creador Francis Galton como una ciencia, aunque, avanzado el siglo $\mathrm{XX}$, quedaron demostradas sus débiles argumentaciones. Los diferentes autores que se han volcado a su estudio prefieren designarla como una pseudo ciencia. Optamos por considerarla bajo la óptica de una "ideología científica” (Sapriza, 2001).

40 El biotipo era la base constitucional del individuo y para establecerlo había que estudiar la herencia familiar, los aspectos morfológicos, funcionales y neuro-psíquico de los antecedentes hereditarios. Implicaba el estudio del aspecto exterior, del desarrollo, la proporción, la función. Asimismo, y, en tercer lugar, estudiar los instintos fundamentales, el sentimiento, las cualidades morales dominantes y las modalidades de la inteligencia.

41 La Ley No. 10.071 "Vagancia, Mendicidad y Estados Afines" es una ley preventiva. Por ella -y sin haber cometido ningún delito- se podía privar de la libertad a los vagos, mendigos, ebrios habituales y toxicómanos, los proxenetas, tahúres y aún aquellos de notoria mala conducta. Interesa destacar el discurso que sustentó la política llevada a cabo por esta dirección resumido en: "Convertir y mantener los Establecimientos de su dependencia en verdaderos claustros de transformación moral y reeducativa del delincuente, cumpliendo su misión de modo de llegar a la mayor disminución posible de la delincuencia y la reincidencia en el delito". A impulso de estas dos destacadas personalidades, Irureta Goyena y Gómez Folle, es que se aprueba la construcción de un Penal "modelo" (como colonia agrícola) en un extenso predio de más de 500 hectáreas a 50 kilómetros de la ciudad capital, en la localidad de Libertad. Debido a los tiempos lentos del país y la falta de recursos, el Penal se terminó de construir en los 70`y fue inaugurado con presos políticos durante la última dictadura cívico militar (1973).

42 En 1935, ya se podían enumerar las realizaciones de la eugenesia en consultorios prenupciales oficinas y Comisiones de Eugenesia. Se mencionaban artículos de la Constitución como realizaciones de esa corriente, entre ellas la "obligación" 
de estar saludable. Se había modificado el Código Penal (1933) y se había promovido el Código del Niño a la luz de la eugenesia. Así, lo habían presentado sus autores en el II Congreso Panamericano de Eugenesia y Homicultura en Buenos Aires, en 1934.

43 Rey Álvarez, S. (1934). La eugenesia en pro del racismo. Ideas y Acción, I, enero, p. 3.

44 Existen testimonios de polémicas anteriores prácticamente desde su instalación. Dan fe de ello una serie de artículos periodísticos y publicaciones católicas e independientes que defienden o atacan la administración tanto del Asilo como de la penitenciaría gobernada por las monjas.

45 Cámara de Representantes de la República del Uruguay (1930). Diario de Sesiones, Tomo CCCLV, agosto de 1929. Montevideo: Imprenta Nacional, p. 450.

46 El circo Sarrasani, fundado en los comienzos del siglo XX en Alemania, se transformó prontamente en una empresa de carácter monumental, icono del fantasioso mundo del espectáculo circense. Realizaba giras por Sudamérica (Brasil, Argentina, principalmente, ocasionalmente, Uruguay, 1925). En 1948, gracias a la intervención de Eva Perón, se convirtió en El Circo Nacional Argentino.

47 Cima, A. (1929). Exposición y critica de nuestro sistema penitenciario. Protección del Estado a las menores abandonadas o delincuentes. Montevideo: Imprenta Nacional Colorada, p. 36.

48 También, es ridiculizado el político Luis Batlle Berres integrante del Consejo del Patronato de Menores por realizar la gestión para que las internas pudieran asistir a una función del Circo de Sarrasani. Posteriormente, y por otras razones, una bailarina del circo terminó en el Asilo. El Demócrata. 21 de Julio de 1929, p. 3. 